\title{
Proteolysis of MLL family proteins is essential for Taspase1-orchestrated cell cycle progression
}

\author{
Shugaku Takeda, ${ }^{1,7}$ David Y. Chen, ${ }^{1,7}$ Todd D. Westergard, ${ }^{1,7}$ Jill K. Fisher, ${ }^{5,7}$ Jeffrey A. Rubens, ${ }^{5}$ \\ Satoru Sasagawa, ${ }^{1}$ Jason T. Kan, ${ }^{1}$ Stanley J. Korsmeyer, ${ }^{5,6}$ Emily H.-Y. Cheng, ${ }^{1,2,3}$ and \\ James J.-D. Hsieh ${ }^{1,2,4,8}$ \\ ${ }^{1}$ Molecular Oncology, Department of Medicine, Washington University School of Medicine, St. Louis, Missouri 63110, USA; \\ ${ }^{2}$ Siteman Cancer Center, Washington University School of Medicine, St. Louis, Missouri 63110, USA; ${ }^{3}$ Department of \\ Pathology and Immunology, Washington University School of Medicine, St. Louis, Missouri 63110, USA; ${ }^{4}$ Department of \\ Molecular Biology and Pharmacology, Washington University School of Medicine, St. Louis, Missouri 63110, USA; ${ }^{5}$ Howard \\ Hughes Medical Institute, Dana Farber Cancer Institute, Harvard Medical School, Boston, Massachusetts 02115, USA
}

\begin{abstract}
Taspase1 was identified as the threonine endopeptidase that cleaves mixed-lineage leukemia (MLL) for proper Hox gene expression in vitro. To investigate its functions in vivo, we generated Taspase $1^{-/}$mice. Taspase1 deficiency results in noncleavage (nc) of MLL and MLL2 and homeotic transformations. Remarkably, our in vivo studies uncover an unexpected role of Taspase 1 in the cell cycle. Taspase $1^{-/}$animals are smaller in size. Taspase $^{-/-}$mouse embryonic fibroblasts (MEFs) exhibit impaired proliferation, and acute deletion of Taspase1 leads to a marked reduction of thymocytes. Taspase1 deficiency incurs down-regulation of Cyclin Es, As, and Bs and up-regulation of $p 16^{\text {Ink4a }}$. We show that MLL and MLL2 directly target E2Fs for Cyclin expression. The uncleaved precursor MLL displays a reduced histone $\mathrm{H} 3$ methyl transferase activity in vitro. Accordingly, chromatin immunoprecipitation assays demonstrate a markedly decreased histone H3 K4 trimethylation at Cyclin E1 and E2 genes in Taspase $1^{-/-}$cells. Furthermore, $M L L^{n c / n c ; 2 n c / n c} M E F s$ are also impaired in proliferation. Our data are consistent with a model in which precursor MLLs, activated by Taspase1, target to Cyclins through E2Fs to methylate histone $\mathrm{H} 3$ at K4, leading to activation. Lastly, Taspase $^{-/-}$cells are resistant to oncogenic transformation, and Taspase 1 is overexpressed in many cancer cell lines. Thus, Taspase1 may serve as a target for cancer therapeutics.
\end{abstract}

[Keywords: Taspase1; MLL; E2F; p16; cell cycle; cancer]

Supplemental material is available at http://www.genesdev.org

Received May 15, 2006; revised version accepted July 11, 2006.

Site-specific proteolyses play central roles in many biological pathways exemplified by the sequential activation of blood coagulation factors, the blood pressure-controlled activation of angiotensinogen, the cholesterolgauged liberation of sterol response element-binding protein (SREBP) from the endoplasmic reticulum (ER) (Brown et al. 2000), the ligand-activated cleavage and subsequent release of the intracellular domain of Notch (Brown et al. 2000), the maturation of the hedgehog signaling molecule (Ye and Fortini 2000), the separation of HCF-1 for proper cell cycle progression (Julien and Herr 2003), and the activation of caspases for cell death ex-

${ }^{6}$ Deceased.

${ }^{7}$ These authors contributed equally to this work.

${ }^{8}$ Corresponding author.

E-MAIL jhsieh@im.wustl.edu FAX (314) 362-1589.

Article is online at http://www.genesdev.org/cgi/doi/10.1101/gad.1449406. ecution (Thornberry and Lazebnik 1998). Identification and characterization of the responsible endopeptidase not only proved critical for a better understanding of such biological processes but also provided targets for intervention of diseases involving specific pathways (Saklatvala et al. 2002).

Taspase 1 was originally cloned as the protease that cleaves mixed-lineage leukemia (MLL) at conserved sites [QV(L)D/GXXD] (Hsieh et al. 2003a). Taspase1 encodes a highly conserved 420-amino-acid proenzyme that is intramolecularly processed to generate an active $\alpha 28 / \beta 22$ heterodimer (Hsieh et al. 2003a). The Taspasel heterodimer displays an overall $\alpha / \beta / \beta / \alpha$ structure and further assembles into an asymmetric $\alpha 2 / \beta 2$ heterotetramer (Khan et al. 2005). Taspase1 is an endopeptidase within a family of enzymes possessing an Asparaginase_2 homology domain. Other members present in prokaryotes and eukaryotes include the amidohydrolases, L-asparaginase, and glycosylasparaginase. L-aspa- 
raginase is involved in asparagine metabolism and glycosylasparaginase participates in the ordered degradation of N-linked glycoproteins by cleaving Asn-GlcNAc linkages that join oligosaccharides to proteins. Taspase1-mediated cleavage of MLL follows distinct aspartate residues, suggesting that Taspase 1 evolved from hydrolyzing asparagines and glycosylasparagines to recognize a conserved peptide motif with an aspartate at the P1 position. The discovery of Taspase1 founded a new class of endopeptidases that utilize the $\mathrm{N}$-terminal threonine of its mature $\beta$ subunit as the active site nucleophile to proteolyze polypeptide substrates after an aspartate. Recently, we demonstrated that Taspase 1 is the long sought-after protease which cleaves the precursor Transcription Factor IIA (TFIIA) $\alpha-\beta$ family proteins (Zhou et al. 2006). TFIIA is composed of three subunits: $\alpha, \beta$, and $\gamma$. The TFIIA $\alpha-\beta$ precursor is translated from a single gene transcript before undergoing post-translational proteolysis to generate heterodimerized mature $\alpha$ and $\beta$ subunits (DeJong and Roeder 1993; Ma et al. 1993; Yokomori et al. 1993). Cleavage of TFIIA $\alpha-\beta$ at the conserved site (QVD/GXXD) regulates its stability but does not affect transcription or embryonic development in Xenopus laevis (Hoiby et al. 2004; Zhou et al. 2006).

Orchestrated expression of Hox genes in vertebrates and homeotic genes in invertebrates determines the segmental body plan in higher organisms (McGinnis and Krumlauf 1992; Capecchi 1997; Kmita and Duboule 2003). Active maintenance of established Hox/homeotic codes requires intricate interplay between antagonistic polycomb group (PcG) and trithorax group (trxG) of proteins (Yu et al. 1998; Hanson et al. 1999; Ringrose and Paro 2004). Although the underlying epigenetic mechanisms are unclear, inherent distinct histone modification activities present in the PcG or trxG proteins containing macromolecular complexes implicate the involvement of the histone code. Trithorax/MLL, the founding member of trxG proteins, exhibits histone $\mathrm{H} 3$ Lys 4 (K4) methyl transferase activity in its C-terminal SET domain (Milne et al. 2002; Nakamura et al. 2002). Several MLL-associated complexes have been reported that methylate histone $\mathrm{H} 3$ at $\mathrm{K} 4$ and acetylate histone H4 at K16 (Petruk et al. 2001; Nakamura et al. 2002; Yokoyama et al. 2004; Dou et al. 2005; Wysocka et al. 2005). Disruption of $M L L$ in mice results in embryonic lethality at embryonic day 10.5 (E10.5), and mice carrying a heterozygous $M L L$-exon3 $3^{\text {lac } Z}$ allele display overt homeotic transformations with altered Hox gene expression (Yu et al. 1995). Recurrent human chromosome band 11q23 translocations disrupting the $M L L$ gene lead to altered $H O X$ gene expression and human leukemias. Leukemogenic MLL translocations fuse the common MLL N-terminal $\sim 1300$ amino acids in frame with $>40$ diverse translocation partners, ranging from transcription factors to cytoplasmic structural proteins (Rowley 1998; Ayton and Cleary 2001; Canaani et al. 2004; Daser and Rabbitts 2004; Gilliland et al. 2004). The unexpected complexity of $M L L$ gene regulation was further illustrated when we and others showed that MLL undergoes proteolysis at the evolutionarily conserved cleavage site 1 (CS1: QVD/GADD) and 2 (CS2: QLD/GVDD) (Yokoyama et al. 2002; Hsieh et al. 2003b). MLL cleavage generates N-terminal $320-\mathrm{kDa}\left(\mathrm{MLL}^{\mathrm{N} 320}\right)$ and C-terminal $180-\mathrm{kDa}\left(\mathrm{MLL}^{\mathrm{C} 180}\right)$ fragments that heterodimerize through conserved domains for downstream gene targeting. RNA interference (RNAi)-mediated knockdown of Taspase1 in HeLa cells indicates the importance of MLL proteolysis in proper Hox gene expression (Hsieh et al. 2003a). However, whether Tapase1 regulates Hox genes in vivo, how Taspase1 affects MLL protein function through site-specific proteolysis, and whether Taspase1 is involved in other biological pathways, remained to be determined.

Here, we report the characterization of Taspase1's functions in vivo. We conclude that Taspasel is the only protease present in mammals that cleaves MLL family proteins. Taspase 1 deficiency leads to homeotic transformations in mice, confirming its participation in Hox gene expression. Remarkably, Taspasel also regulates the cell cycle, thus controlling organism size. It directly participates in cell cycle gene expression through the MLL-E2F axis. Proteolysis of MLL family proteins by Taspase1 is required to fully activate their histone methyl transferase (HMT) activity. Our study establishes a novel paradigm in which an endopeptidase orchestrates cell cycle progression through site-specific proteolysis.

\section{Results}

\section{Generation of Taspase $1^{-/-}$mice}

To assess Taspase1's functions in a whole organism setting, we generated Taspase1-null mice. A cre-lox gene targeting strategy was employed to delete exon 9 of murine Taspase1, where the active site Thr 234 resides (Fig. 1A). Successful targeting was verified by Southern blot and PCR analyses (Fig. 1B,C). Deletion of exon 9 resulted in the disappearance of Taspase1 protein in Taspase $1^{-/-}$ mouse embryonic fibroblasts (MEFs) (Fig. 1D) and whole embryo extracts (data not shown), excluding the possibility of introducing a dominant-negative effect in Taspase $1^{-/-}$animals. Most importantly, no cleaved MLL ${ }^{\mathrm{C} 180}$ was detected in Taspase $1^{-/-}$cells. In the absence of Taspase1, MLL exists as a full-length precursor protein $\left(\mathrm{MLL}^{\mathrm{FL}}\right.$ ) (Fig. 1D). Although conserved Taspase1 cleavage sequences exist among MLL family proteins, MLL is the only proven substrate. In mammals, there is one additional trithorax homolog, MLL2, which contains all of the architecturally positioned conserved domains as MLL (Fig. 1E; Huntsman et al. 1999). Although MLL2 has been suggested to undergo proteolysis, it remains undetermined whether it is also processed by Taspase 1 (Hughes et al. 2004). In the absence of Taspase1, no processed MLL2 ${ }^{\mathrm{C} 85}$ was detected (Fig. 1D). The site-specific cleavage of $\mathrm{MLL}^{\mathrm{FL}}$ and MLL2 ${ }^{\mathrm{FL}}$ in Taspase $1^{-/-}$cellular extracts was successfully restored when recombinant Taspase1 (rTaspase1) was exogenously added (Fig. 1D). 


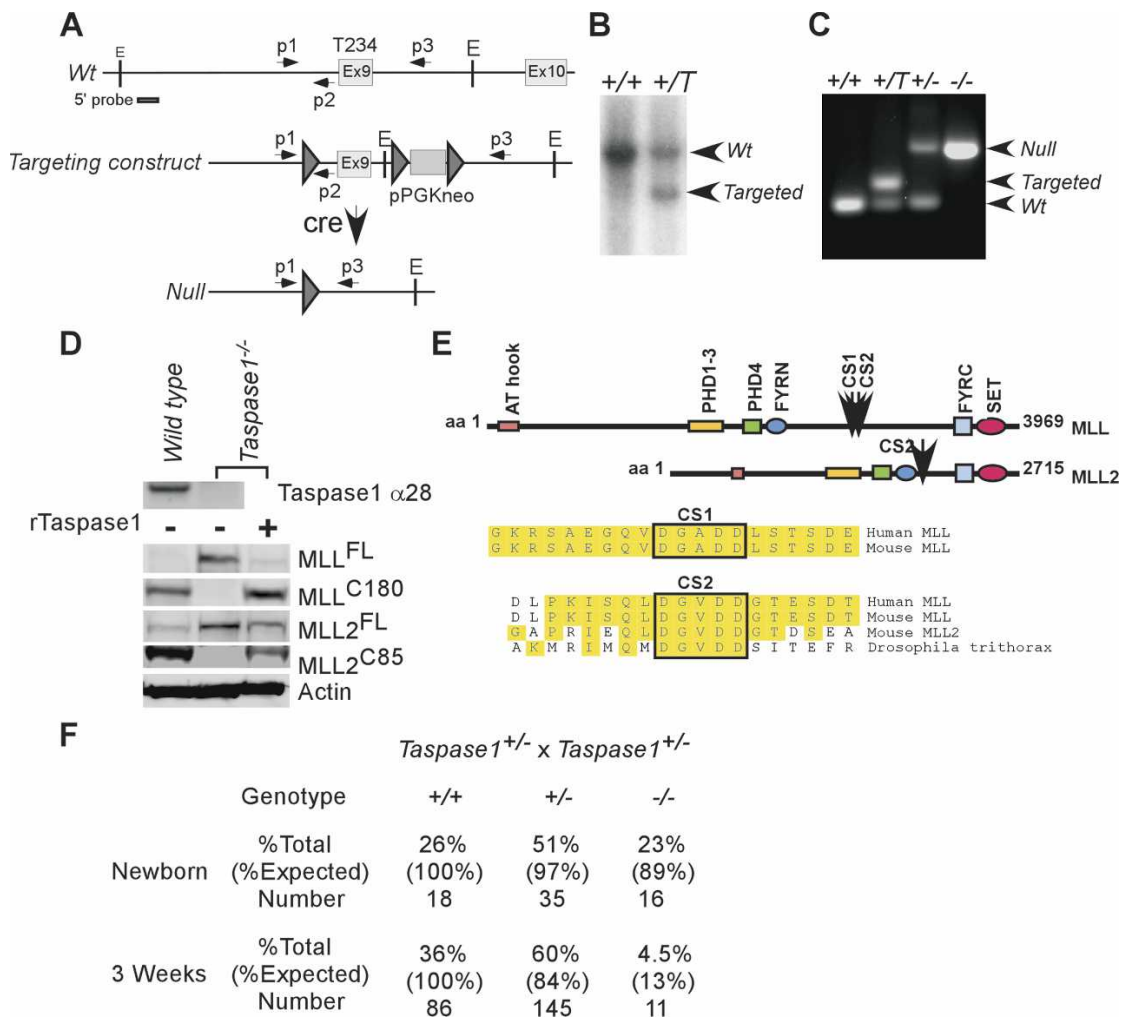

Figure 1. Generation of Taspase1-null mice. (A) Schematic representation of the murine Taspase1 endogenous locus (top), targeting construct (middle), and exon 9-deleted null allele (bottom). Targeted (T) allele was first derived in RW4 ES cells by homologous recombination, followed by transient expression of cre recombinase to generate the null allele. (Solid triangles) loxP sites; (E) EcoRI sites; (Ex) exon. P1, p2, and p3 designate the primer set used for PCR to distinguish Wild-type (Wt), Targeted, and null alleles. (B) Southern blot analysis of ES cells using a $5^{\prime}$ probe detects 8.1 - and 5.6-kb EcoRI fragments derived from wild-type and $T$ alleles, respectively. $(C)$ Genotypic analysis of ES cells carrying various Taspase1 alleles by PCR. P1 and p2 generate 190- and 230-bp products from wild-type $(\mathrm{Wt})$ and Targeted alleles, respectively. Under our PCR conditions, $\mathrm{p} 1$ and $\mathrm{p} 3$ do not detect the wild-type allele; however, upon exon 9 deletion, they produce a 480-bp product from the resulting null allele. $(D)$ Taspase1 is undetected in Taspase $1^{-/-}$MEFs by Western blot using anti- $\alpha 28$ Taspase 1 antibody. Processed C-terminal fragments of MLL $\left(\mathrm{MLL}^{\mathrm{C} 180}\right)$ and MLL2 (MLL2 ${ }^{\mathrm{C} 85}$ ) are not detected in the absence of Taspase 1 with a reciprocal increase of full-length precursor MLL (MLL ${ }^{\mathrm{FL}}$ ) and MLL2 (MLL2 ${ }^{\mathrm{FL}}$ ). Incubation of Taspase $1^{-/-}$cellular extracts with rTaspase1 restores the proteolysis of endogenous MLL ${ }^{\mathrm{FL}}$ and MLL2 ${ }^{\mathrm{FL}}$. (E) Diagram depicts similar architecturally positioned conserved domains of MLL and MLL2. Sequence alignment demonstrates the conservation of cleavage sites 1 and 2 (CS1 and CS2) among MLL family proteins. (F) Genotypic analyses demonstrate a profound early postnatal lethality of Taspase $1^{-/-}$mice.

Taken together, Taspase1 is the only protease responsible for the proteolysis of MLL family proteins.

No evident gross abnormalities were observed in mice with haploinsufficiency of Taspase1. Intercrosses between Taspase $1^{+/-}$mice provided the first assessment of Taspase1's functions in vivo. A minor embryonic developmental disadvantage was noted among Taspase $1^{-/-}$ newborns (89\% of expected Mendelian ratio) (Fig. 1F). Taspase $1^{-/-}$animals were born with no apparent respiratory distress. However, the majority died at postpartum day 1 or 2 (P1 or P2) with no obvious milk spots, suggesting a feeding defect. This profound early postnatal lethality of Taspase $1^{-/-}$animals resulted in a $13 \%$ survival at 3 wk of age (Fig. 1F).

\section{Taspase1-deficient animals exhibit classic homeotic transformations}

Our prior studies indicated a role of Taspase1 in Hox gene expression in vitro. To assess whether Taspase1 deficiency incurs homeotic transformations from altered Hox gene expression, axial skeletons of P1 wild-type, Taspase $1^{+-}$, and Taspase $1^{-/-}$newborns were examined (Fig. 2). Remarkably, Taspase $1^{-/}$animals displayed profound skeletal abnormalities with high degrees of penetrance (Fig. 2I). Intermediate phenotypes were also observed among Taspase $1^{+/-}$animals. Identified abnor- malities representing classic homeotic transformations included a broadened and tilted anterior arch of atlas $(\mathrm{C} 1$ vertebra) (a.a.a.), a split neural arch of axis (C2 vertebra), a posterior transformation of $\mathrm{C} 7$ to $\mathrm{T} 1$ with attached outgrowing aberrant ribs, an incomplete segmentation between sternebrae 3 and 4, an anterior transformation of $\mathrm{T} 8$ to $\mathrm{T} 7$ with resulting additional pairs of sternal ribs, and an anterior transformation of L1 to T13 with resulting 14 pairs of ribs (Fig. 2). Taken together, Taspase1 confers correct segmental identities.

\section{Taspase $1^{-/-}$animals and embryos are smaller in size}

Remarkably, all Taspase ${ }^{-/-}$newborns can be easily identified right after birth because they are markedly smaller in size. Taspase $1^{-/-}$animals that survived the newborn period were smaller through adulthood, compared with their wild-type and heterozygous littermates (Fig. 3A). This phenotype commences in uteri. Taspase $1^{-/}$embryos are significantly smaller at E18.5 (Fig. 3B). This abnormality can be detected as early as E14.5 (data not shown). Such a phenotype is commonly associated with deregulation of signaling pathways controlling cell growth and/or cell proliferation. FACS analyses did not detect any cell size alteration in Taspase $1^{-/-}$ MEFs, compared with wild-type MEFs (Fig. 3C). 
Takeda et al.

Figure 2. Homeotic transformations of axial skeletons in Taspase $1^{-/-}$mice. Skeletal comparison between wild-type $(A-D)$ and Taspase $1^{-/}(E-H) \mathrm{P} 1$ newborn are illustrated. Bones are stained as red and cartilage as blue with alazarin red and alcian blue, respectively. $(A, E)$ Lateral views of cervical $(C)$ and upper thoracic $(T)$ regions demonstrate deformed a.a.a., split C2 neural arch (arrow), and posterior transformation of $\mathrm{C} 7$ with an additional rib (arrowhead) in Taspase1 $1^{-/}$but not wild-type skeletons. $(B, F)$ Magnified frontal views of the a.a.a.. The asterisk denotes deformed and broadened a.a.a. in Taspase $1^{-/-}$mice. $(C, G)$ Anterior views of the sternum indicate incomplete segmentation between sternebrae 3 and 4 (arrowhead), and an additional pair of sternal ribs fused between sternebra 4 and xiphoid process present in Taspase $1^{-/-}$but not wild-type newborns. $(D, H)$ Anterior views of lower thoracic and lumbar vertebrae demonstrate Taspase1 deficiency resulted in anterior transformation of $\mathrm{L} 1$ with one additional pair of ribs (arrow). (I) Summary of skeletal defects observed in Taspase1-deficient newborns.

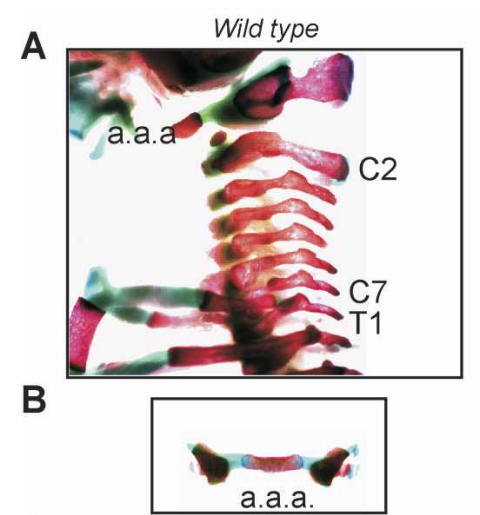

C
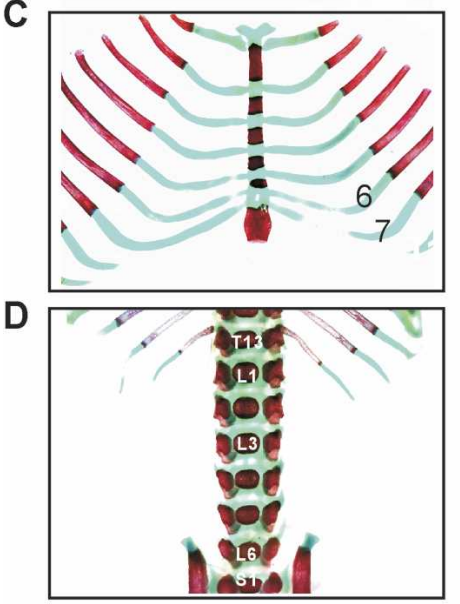

I

a.a.a., tilted, broadened, and deformed

C2, split neural arch

C7, posterior transformation

T8, anterior transformation

Sternebrae 3 and 4 , incomplete segmentation

$\mathrm{L} 1$, anterior transformation

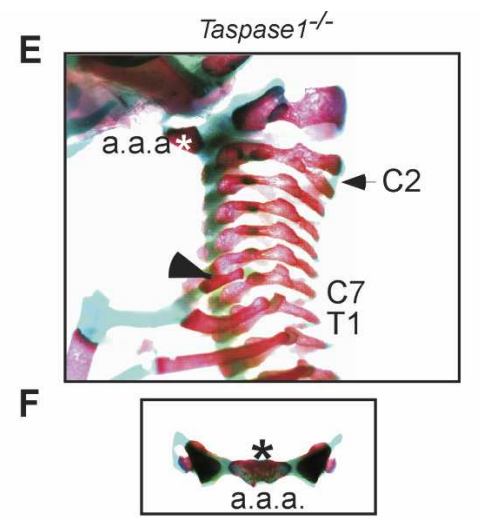

G

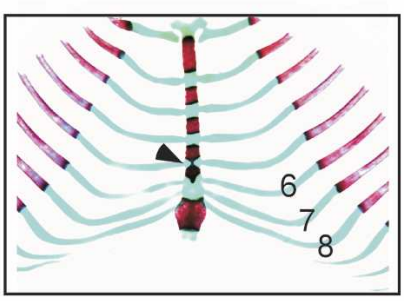

$\mathrm{H}$

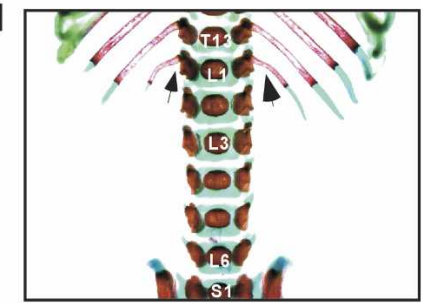

$+/+(n=16) \quad+/(n=18) \quad-/(n=16)$

$0 \%(0) \quad 16.7 \%(3) \quad 87.5 \%(14)$

$0 \%(0) \quad 16.7 \%(3) \quad 18.8 \%(3)$

$6.3 \%(1) \quad 0 \%(0) \quad 18.8 \%(3)$

$0 \%(0) \quad 0 \%(0) \quad 31.3 \%(5)$

$12.5 \%(2) \quad 27.8 \%(5) \quad 37.5 \%(6)$

$0 \%(0) \quad 0 \%(0) \quad 56.3 \%(9)$
Requirement of Taspase 1 for the proliferation of MEFs and thymocytes

To further investigate the underlying mechanism by which Taspase 1 regulates animal size, we next examined cell proliferation. Compared with wild-type MEFs, the cell number was threefold lower in Taspase $1^{-/}$cells after $7 \mathrm{~d}$ in culture (Fig. 4A). This difference does not result from increased cell death determined by Annexin V staining (Fig. 4B). Pulse labeling with BrdU demonstrated that Taspase $1^{-/}$MEFs have fewer BrdU-positive S-phase cells $(18.2 \pm 1.5 \%)$ than wild-type MEFs $(31 \pm 2.8 \%)$ (Fig. 3C). Taspase1 is abundantly expressed in thymus (Supplementary Fig. S1) where thymocytes undergo maturation and rapid cell division. The profound defects in Taspase $1^{-/-}$MEFs prompted us to examine its role in thymocyte expansion. We asked whether induced acute deletion of Taspase 1 in vivo affects thymocyte proliferation. We employed the MxCre recombinase mouse model in which the expression of Cre recombinase can be induced upon polyinosinic-polycytidylic acid (pI-pC) injection, resulting in a deletion of the floxed $(f)$ conditional allele (Kuhn et al. 1995). In MxCre+;Taspase $1^{f /-}$ mice, acute deletion of Taspase 1 in the thymus (Fig. 4D) led to a $50 \%$ reduction of thymus weight (Fig. 4E) and a 54\% reduction of total thymocyte number (Fig. 4F), compared with control littermates. The T-cell development in the thymus can be divided into three sequential stages-double-negative (DN), double-positive (DP), and single-positive (SP) stages-based on their cell surface expression of CD4 and CD8. DP cells constitute the majority of thymocytes, resulted from exponential cell division (Paul 2003). Acute deletion of Taspase 1 did not reduce the DN population, but instead, led to a $60 \%$ reduction of DP thymocytes (Fig. 4F). Annexin $\mathrm{V}$ staining did not detect an increase of cell death in thymocytes upon Taspase1 deletion (Fig. 4G). These data indicate that the removal of Taspasel in the thymus leads to a profound proliferation block during DP expansion. 


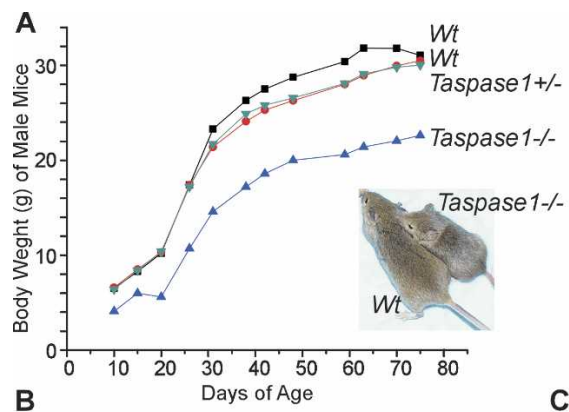

$$
\text { B }
$$

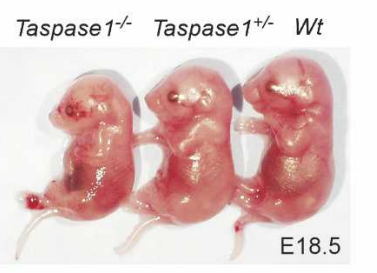

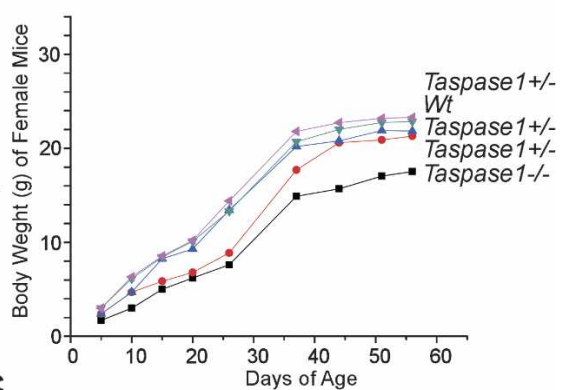

C

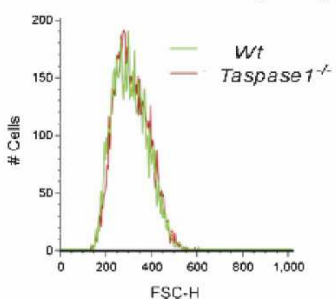

Figure 3. Taspase1 deficiency results in animals with small body size. (A) Taspase $1^{-/}$mice were born smaller and remained smaller through adulthood. Photo insert was taken at $8 \mathrm{wk}$ of age. All of the Taspase1 newborns $(n=10)$ and adults $(n=6)$ examined are significantly smaller than their littermates. (B) Taspase $1^{-/}$ E18.5 embryo is significantly smaller than its wild-type $(\mathrm{Wt})$ and Taspase $1^{+/-}$littermates. (C) FACS analysis detects no differences in cell size between wild-type and Taspase-1 $1^{-/}$primary MEFs. Representative data from three independent experiments are presented.
Deregulated cell cycle gene expression in Taspase1-deficient cells

After establishing an essential role of Taspasel in the proliferation of both MEFs and thymocytes, we investigated the underlying mechanisms by which Taspase 1 regulates cell division. Cell cycle progression is governed by the coordinated assembly of Cyclin/Cdk complexes, through oscillated Cyclin expression, to activate E2Fs for proper expression of essential cell proliferation genes (Dyson 1998; Nevins 2001; Trimarchi and Lees 2002; Blais and Dynlacht 2004; Bracken et al. 2004). Further regulation of the Cyclin/Cdk activities is imposed by Cdk inhibitors (CdkIs) (Sherr and Roberts 1999). Quantitative RT-PCR assays on asynchronized Taspase ${ }^{-/-}$ MEFs revealed a profound underexpression of $E, A$, and $B$, but not $D$ types of Cyclins, a marked overexpression of $p 16^{\operatorname{Ink} 4 a}$, and a moderate elevation of $p 21, p 27$, and $A R F$ (Fig. 5A,B). Similar data were obtained when protein levels were determined (Supplementary Fig. S2). As p $16^{\text {Ink4a }}$ expression is highly elevated, the reduction of expression of Cyclins $E, A$, and $B$ may simply reflect fewer cycling cells. Alternatively, Taspase 1 may directly regulate the Cyclin expression. To discern these possibilities, we cultured MEFs in the presence of BrdU for 24 $\mathrm{h}$ to label all of the cycling cells. A $10 \%$ increase of quiescent cells was observed in Taspase $1^{-1-}$ MEFs (Supplmentary Fig. S3), which cannot be held accountable for the $60 \%$ reduction in Cyclin E1 and E2 expression. Accordingly, these data suggest that Taspase1 participates in the regulation of $p 16^{\text {Ink } 4 a}$ and Cyclins. To further determine the significance of $\mathrm{p} 16^{\mathrm{INK} 4 \mathrm{a}}$ overexpression in the observed cell cycle defects of Taspase $1^{-/-}$cells, we performed RNAi-mediated knockdown of p16 $6^{\mathrm{INK} 4 \mathrm{a}}$. Expression of the $\mathrm{p} 16^{\mathrm{INK} 4 \mathrm{a}}$ short hairpin RNA (shRNA) in Taspase $1^{-/}$MEFs reduced the amounts of $\mathrm{p} 16^{\mathrm{INK} 4 \mathrm{a}}$ to near wild-type levels (Supplementary Fig. S4). The reduced $\mathrm{p} 16^{\mathrm{INK} 4 \mathrm{a}}$ expression in Taspase $1^{-/-}$cells partially rescued the proliferation defects (Fig. 5C,D). This partial rescue confirms $\mathrm{p} 16^{\mathrm{INK} 4 \mathrm{a}}$ as an important but not the sole Taspasel downstream cell cycle regulator. Since p16 ${ }^{\text {Ink4a }}$ up-regulation is commonly associated with early replicative senescence (Itahana et al. 2001), we performed senescence-associated galactosidase (SA-Gal) assays on passage 2 Taspase $1^{-/}$MEFs that were used for all of the assays presented, and did not detect SA-Galpositive cells (data not shown). Following a 3T9 protocol, Taspase $1^{-1-}$ MEFs manifested replicative senescence at passage 8 , compared with wild-type cells, which senesced at passage 10 (data not shown).

The up-regulated $\mathrm{p} 16^{\text {Ink4a }}$ and down-regulated Cyclin E expression in Taspase $1^{-/-}$cells predicts a block in G1/S transition, and may pose a higher threshold for G0 to G1 re-entry. To test these hypotheses, primary MEFs were synchronized by serum deprivation, and cell cycle reentry was determined by Tritium thymidine incorporation. Indeed, upon full serum stimulation, serumdeprived quiescent Taspase $1^{-/-}$cells displayed a 2-h delay in S-phase entry (Fig. 5E). As p16 ${ }^{\text {Ink4a }}$ inhibits Dtype Cdks, we next determined the activity of D-type Cdks in Taspase $1^{-/-}$cells by examining Rb phosphorylation at Ser 807/811. Taspase $1^{-/}$cells displayed a delayed and impaired $\mathrm{Rb}$ phosphorylation (Fig. 5F). This observed delay is similar to that of cells deficient for all three $D$ type Cyclins $(D 1, D 2$, and $D 3)$ (Kozar et al. 2004). The marked reduction of total Tritium thymidine incorporation in Taspase $1^{-/-}$MEFs (Fig. 5E) indicates a significant decrease of cells re-entering the cell cycle, which was further confirmed by long-term BrdU labeling experiments (Fig. 5G). Sequential induction of Cyclins, namely D, E, A, followed by B, with consequent activation of respective Cyclin/Cdk complexes, governs the cell cycle progression. We next determined the induction of D, E, and A types of Cyclins after serum restimulation and confirmed the impairment of induction of Cyclins E and A, but not D (Fig. $5 \mathrm{H}$ ), which is consistent with our prior analyses on asynchronized cells. 
Uncleaved precursor $M L L^{F L}$ exhibits impaired histone H3 methyl transferase activity

MLL is one of the best characterized mammalian methyl transferase that specifically methylates histone $\mathrm{H} 3$ at the K4 position that marks active gene expression (Milne et al. 2002; Nakamura et al. 2002; Santos-Rosa et al. 2002). To investigate how Taspasel deficiency affects the transcription of cell cycle genes, we focused our attention on the regulation of $p 16^{\text {Ink } 4 a}$, Cyclin E1, and E2 at the chromatin level to determine whether the known Taspase1 substrate, MLL, directly participates in the cell cycle gene regulation. Indeed, chromatin immunoprecipitation (ChIP) assays demonstrated the occupancy of MLL protein on Cyclin E1 and E2 genes (Fig. 6A). Consequently, histone $\mathrm{H} 3 \mathrm{~K} 4$ trimethylation of target genes was examined to investigate whether noncleavage of MLL altered its methyl transferase activity. A marked reduction of $\mathrm{H} 3 \mathrm{~K} 4$ trimethylation at Cyclin E1 and E2 was observed in Taspase $1^{-/}$cells, which is accountable for their decreased expression (Fig. 6A). As more and more cross-talks between histone modifications are recognized, we tested whether the altered H3 K4 methyl- ation affects modifications on adjacent K9/14 (Fig. 6A). ChIP assays demonstrated a moderate reduction of histone $\mathrm{H} 3 \mathrm{~K} 9 / 14$ acetylation at Cyclin E1 and E2 genes (Fig. 6A). The demonstration of a reduction, but not a loss of H3 K4 methylation, suggests that MLL family proteins need to be cleaved by Taspasel to be fully functional. To examine this possibility, we first immunoprecipitated MLL protein in cellular extracts derived either from wild-type or Taspase $1^{-/-}$MEFs. Bead-bound immunoprecipitated MLL was incubated with purified histone H3 and S-Adenosyl-(methyl- $\left.{ }^{3} \mathrm{H}\right)$ Methionine before SDSPAGE analysis. HMT activity was then assessed by autoradiography. A near $50 \%$ reduction of HMT activity was observed in Taspase $1^{-/-}$cells, compared with wildtype cells (Fig. 6B). To ensure that the observed activity reduction is not due to a decreased ability to immunoprecipitate the uncleaved precursor $\mathrm{MLL}^{\mathrm{FL}}$, we determined the amounts of bead-bound MLL ${ }^{\mathrm{FL}}$ protein. The poor gel transferring physical property of the $500-\mathrm{kDa}$ $\mathrm{MLL}^{\mathrm{FL}}$ makes it impossible to perform a direct comparison between the immunoprecipitated amounts of MLL ${ }^{\mathrm{FL}}$ and processed MLL. To overcome this technical difficulty, we incubated bead-bound $\mathrm{MLL}^{\mathrm{FL}}$ with $2 \mu \mathrm{g}$ of

Figure 4. Cell cycle defects associated with the loss of Taspase1. (A) Taspase $1^{-/-}$MEFs exhibit impaired proliferation. Replicate cultures of $1 \times 10^{5}$ cells per $6-\mathrm{cm}$ dish were plated on day 0 , and cells were counted each day for seven consecutive days. Data shown as mean $\pm \mathrm{SD}$ were obtained from three independent lines of wild-type $(\mathrm{Wt})$ and Taspase $^{-/-}$primary MEFs at passage 2. (B) Annexin $\mathrm{V}$ staining demonstrates similar baseline cell death between wild-type $(\mathrm{Wt})$ and Taspase $1^{-/}$primary MEFs. Data shown as mean \pm SD were obtained from three independent experiments. (C) Taspase $1^{-/-}$MEFs have fewer S-phase cells. BrdU incorporation was determined by FACS analysis, and representative data of three independent experiments are presented. Mean \pm SD from three independent experiments are as follows: wild type (Wt) (G1: $48.5 \pm 3.2 \%$; : $31.0 \pm 2.8 \%$; G2/M: $19.1 \pm 0.4 \%$ ) vs. Taspase1 $^{-/}$(G1: $57.9 \pm 2.6 \%$; S: $18.2 \pm 1.5 \%$; G2/M: $22.1 \pm 2.9 \%)$. (D) pI-pC injection induces efficient deletion of Taspase 1 in the thymus. The extent of acute deletion of floxed $(f)$ Taspase1 allele was assessed by PCR on genomic DNA obtained from the tail before pI-pC injection and from thymocytes after pI-pC injection (+). (E) Thymus weight was measured after MxCre induction by pI-pC injections. (F) Numbers of total and subsets of thymocytes after acute deletion of Taspase 1 by $\mathrm{pI}-\mathrm{pC}$ injections are presented. The percentages of DN, DP, and SP thymo-

A
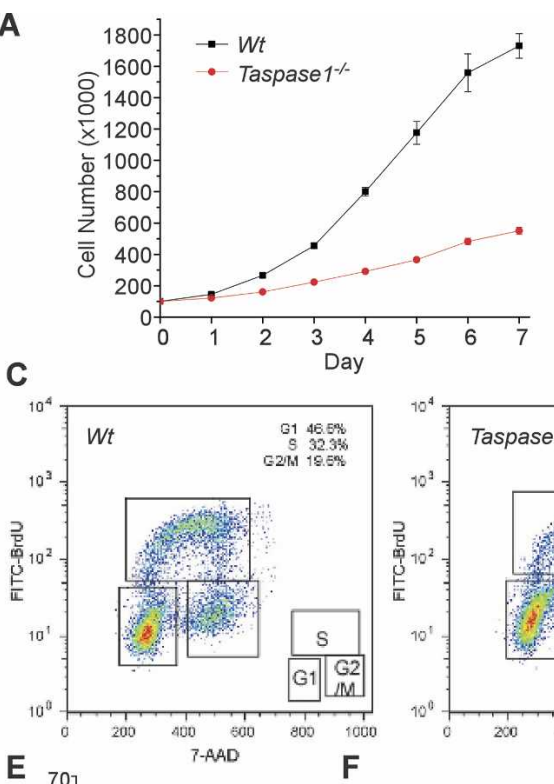

E

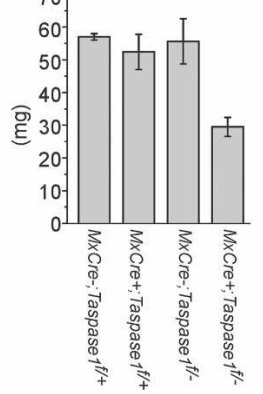

B
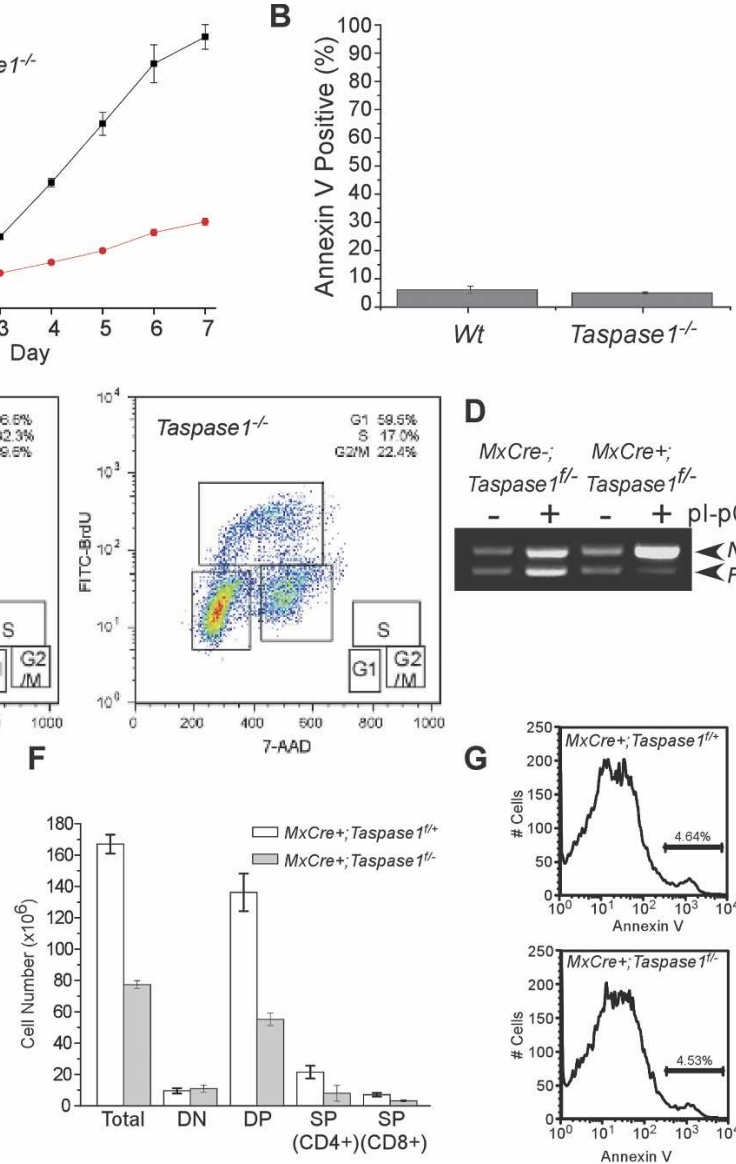

D MxCre-; MxCre+;

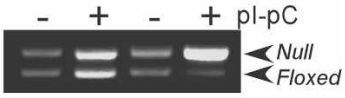
G
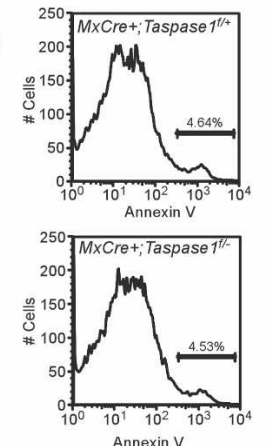

cytes were obtained by FACS analysis of CD4 and CD8 expression. Numbers of each subset of thymocytes are obtained by multiplying the total thymocyte number by the respective percentage. $(G)$ Baseline cell death of thymocytes after pI-pC injections was determined by Annexin V staining. Representative data from three independent experiments are presented. Data shown in $E$ and $F$ as mean \pm SD were obtained from three mice of each indicated genotype. 
rTaspase 1 for $6 \mathrm{~h}$ to ensure complete processing before SDS-PAGE and anti-MLL Western blot analyses (Fig. 6C). We confirmed that there were an equal number of moles of $M_{L L}{ }^{\mathrm{FL}}$ and processed MLL utilized in our HMT assays (Fig. 6C). Taken together, the uncleaved precursor MLL ${ }^{\mathrm{FL}}$ apparently is hypomorphic. This is in accordance with genetic observations obtained with a Drosophila trithorax hypomorphic E3 $\left(\operatorname{trx}^{E 3}\right)$ allele in which an internal in-frame deletion removes a predicted Taspase 1 cleavage site and encodes a noncleavable trithorax (Mazo et al. 1990).

In an attempt to understand how Taspase1 deficiency resulted in the activation of $p 16^{\text {Ink } 4 a}, \mathrm{ChIP}$ assays on $p 16^{\text {Ink } 4 a}$ gene were performed and an increased MLL targeting was observed (Fig. 6A). However, no significant changes on histone H3 K4 trimethylation and H3 K9/14 acetylation were detected on the $p 16^{\text {Ink } 4}$ gene (Fig. 6A), supporting the notion that up-regulation of $\mathrm{p} 16^{\text {Ink4a }}$ may not be achieved by MLL-mediated histone modification. MLL has been shown to form complexes with multiple nuclear factors involved in gene regulation (Popovic and Zeleznik-Le 2005). Increased MLL targeting may facilitate recruiting these factors to $p 16^{\text {Ink } 4 a}$, which leads to its activation. Alternatively, noncleavage of yet identified protein substrate(s) of Taspase1 may contribute to the transcriptional activation of $p 16^{\text {Ink } 4 a}$. It has been shown that PcG protein, Bmi, regulates $\mathrm{p} 16^{\text {Ink } 4 \text { a }}$ expression (Jacobs et al. 1999). Our findings on MLL targeting to the $p 16^{\text {Ink } 4 a}$ gene suggest that both PcG and trxG proteins may coordinately regulate not only Hox genes but also cell cycle genes.
A
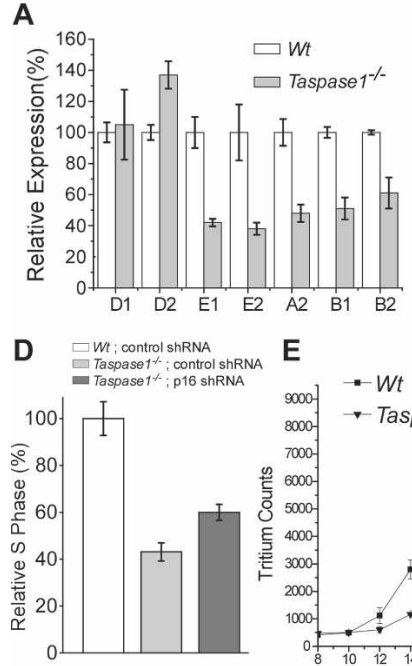

G

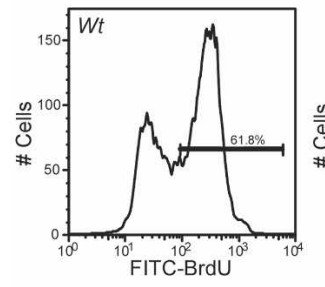

B

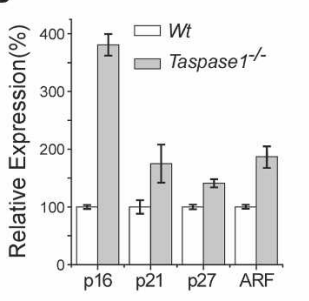

C

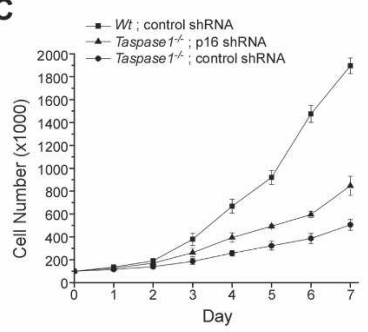

$\mathrm{F}$

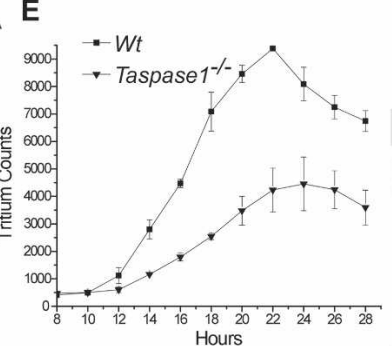

\section{Wt}

Taspase $1^{-1-}$

$2810121518 \quad 2810121518$ Hour
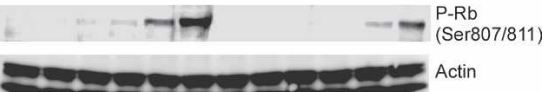

$\mathrm{H}$

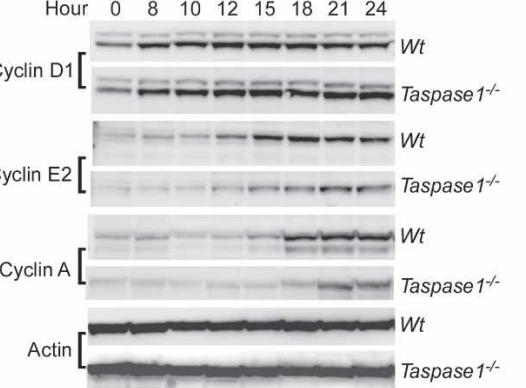

Figure 5. Taspase 1 deficiency results in deregulated expression of cell cycle genes. $(A, B)$ Quantitative RT-PCR analyses of $C y c l i n s$ $(A)$ and $C d k I s$ and $A R F(B)$ on asynchronized primary MEFs are presented. The expression levels in wild-type (Wt) cells are set at $100 \%$. $(C, D)$ Knockdown of $p 16$ in Taspase $1^{-1-}$ MEFs partially rescued the proliferation defect associated with the loss of Taspase1. (C) Triplicate cultures of $1 \times 10^{5}$ cells per $6-\mathrm{cm}$ dish were plated on day 0 , and cells were counted each day for seven consecutive days. (D) S-phase cells were determined by pulse labeling with BrdU before being subjected to FACS analysis using FITC-conjugated anti-BrdU antibody. Results are shown as relative to proliferation of wild-type (Wt) cells infected with control shRNA, which was set as $100 \%$. Data shown as mean \pm SD were obtained from wild-type and Taspase $1^{-1-}$ primary MEFs infected with lentivirus expressing indicated shRNA. ShRNA against firefly luciferase was used as a negative control. (E) Serum-deprived quiescent primary MEFs were restimulated with medium containing 10\% FBS for indicated periods of time. Tritium thymidine uptake was obtained to assess cell cycle re-entry from G0. (F) Taspase $1^{-/-}$MEFs display delayed and impaired D-type Cdks-mediated Rb phosphorylation. Primary MEFs at passage 2 were synchronized with serum deprivation before being refed with full serum for the indicated periods of time. Cellular

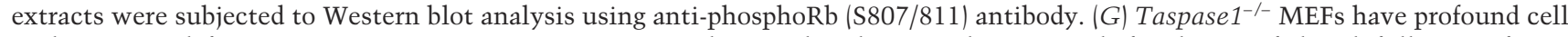
cycle re-entry defects. Primary MEFs at passage 2 were synchronized with serum deprivation before being refed with full serum for 28 $\mathrm{h}$ in the presence of BrdU. Cycling cells were assessed with anti-BrdU FITC-conjugated antibody. Representative data from three independent experiments are presented. $(H)$ Taspase $1^{-/}$MEFs exhibit delayed and impaired induction of Cyclin E, and A, but not D. Serum-deprived quiescent passage 2 primary MEFs were restimulated with medium containing $10 \%$ FBS for indicated periods of time. Expression of cyclins was examined by Western blot analyses. 
$M L L$ proteins target different subsets of E2Fs for downstream gene regulation

E2F family proteins are the key molecules in orchestrating the activation of essential cell cycle progression genes including Cyclins $E, A$, and $B$ (Dyson 1998; Nevins 2001; Trimarchi and Lees 2002; Blais and Dynlacht 2004; Bracken et al. 2004). Since the altered Cyclin gene expression profile in Taspase1-null cells mirrored the defects associated with impaired E2F activities, we envisioned that cleaved MLL might target to these Cyclin genes through E2Fs in that MLL has no sequence-specific DNA-binding ability. Potential interactions between MLL and all six E2F family members were examined by coimmunoprecipitation assays. Remarkably, MLL interacts with E2F2, E2F4, and E2F6 with different affinities (Fig. 7A). Of note, E2F6 was recently copurified with MLL in the WDR5-associated protein complex (Dou et al. 2005). As MLL2 shares all the conserved domains with MLL, interactions between MLL2 and E2Fs were also tested. Surprisingly, MLL2 binds to a different subset of E2Fs, namely E2F2, E2F3, E2F5, and E2F6 (Fig. 7B). Distinct interactions between E2Fs and MLLs suggest unique yet redundant roles played by individual MLL proteins in the cell cycle regulation. To further characterize the interaction between MLL and E2F2, deletion mutants of E2F2 were coexpressed with MLL before subjected to coimmunoprecipitation assays. We mapped the marked box and leucine zipper-containing region (amino acids 200-349) of E2F2 that mediates its interaction with MLL (Fig. 7C). Direct interactions were confirmed by GST pull-down assays. GST-E2F2 (amino acids 210-349) specifically coprecipitated fragments of MLL that encode conserved domains, amino acids 1401-2158 and amino acids 3656-3969 (Fig. 7D). E2F proteins have been divided into activator E2Fs (E2F1, E2F2, and E2F3a) and repressor E2Fs (E2F3b, E2F4, E2F5, and E2F6). As MLLs interact with both classes of E2Fs, it is conceivable that these interactions may contribute to organized activation of E2F targets in addition to Cyclins. Interestingly, recent studies also revealed the roles of $\mathrm{E} 2 \mathrm{~F}$ proteins in the expression of Hox genes and E2F6 deficiency leads to homeotic transformations in mice (Storre et al. 2002).

MEFs bearing noncleavable alleles of MLL and MLL2 are impaired in proliferation

The altered histone H3 K4 trimethylation, the direct MLL targeting, and the direct interactions between MLLs and E2Fs support the hypothesis that MLL proteins are crucial substrates for Taspasel in regulating cell cycle progression. To investigate the biological significance of MLL and MLL2 proteolysis, we generated knock-in mice bearing homozygous noncleavable alleles (nc) of $M L L$ and/or MLL2 in which Taspase1 cleavage sequences are mutated (data not shown). The absence of individual proteolysis in MEFs derived from $M L L^{n c / n c}$ and/or $M L L 2^{n c / n c}$ knock-in mice was confirmed by Western blot analyses (Fig. 8A). Proliferation curves were obtained with primary MEFs carrying homozygous $M L L$
A
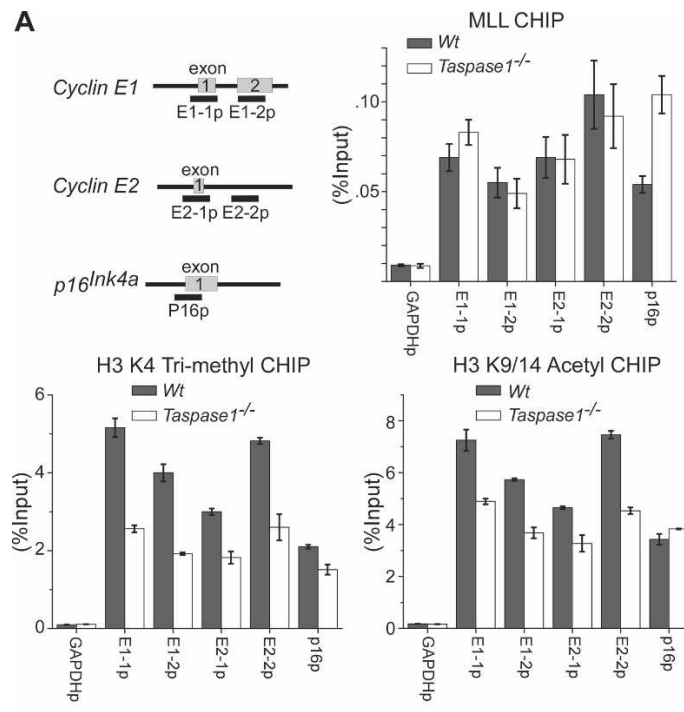

$\mathrm{H} 3 \mathrm{~K} 9 / 14$
$\quad W_{t}$

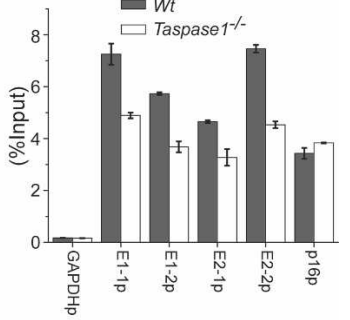

B

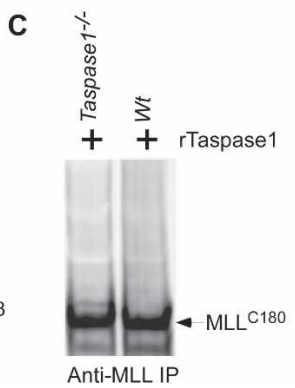

Figure 6. Taspase 1 activates MLL HMT activity through sitespecific proteolysis. (A) ChIP assays on Cyclin E1, E2, and $p 16^{\text {Ink } 4 a}$ genes were performed using indicated antibodies. TaqMan probes are outlined (E1-1p and E1-2p for Cyclin E1, E2-1p and E2-2p for Cyclin E2, and p16p for p16 $\left.{ }^{\text {Ink4a }}\right)$. Data shown as mean \pm SD were obtained from three independent experiments performed using passage 2 primary MEFs. $(B)$ In vitro HMT assays were performed using cellular extracts with indicated genotypes. Bead-only mock immunoprecipitation, without the addition of anti-CT MLL antibody, served as a negative control. Activity was quantified by densitometry, and the activity of wild-type (Wt) cells was arbitrarily set at 1 . Representative data from three independent experiments are presented. $(C)$ Equal amounts of immunoprecipitated MLL proteins were utilized in the HMT assays. Bead-bound MLL proteins were subjected to in vitro Taspase1 cleavage before being analyzed by SDS-PAGE and anti-CT MLL Western blots.

and/or MLL2 noncleavable alleles (Fig. 8B). Noncleavage of MLL, but not MLL2 alone, led to a significant proliferation defect. However, the specific role of MLL2 cleavage in cell proliferation was evident in that further impairment in proliferation was observed in cells carrying combined homozygous $M L L$ and $M L L 2$ noncleavable alleles $\left(M L L^{n c / n c} ; 2^{n c / n c}\right)$. However, the proliferation defect appeared more profound in Taspase $1^{-1-}$ than $M L L^{n c / n c}$; $2^{n c / n c}$ cells. These data raise the possibility that Taspase1 processes additional substrate(s) other than MLL and MLL2 to fully coordinate cell cycle progression. Our data are consistent with a model in which MLLs, following a cleavage-mediated activation by Taspase1, target 


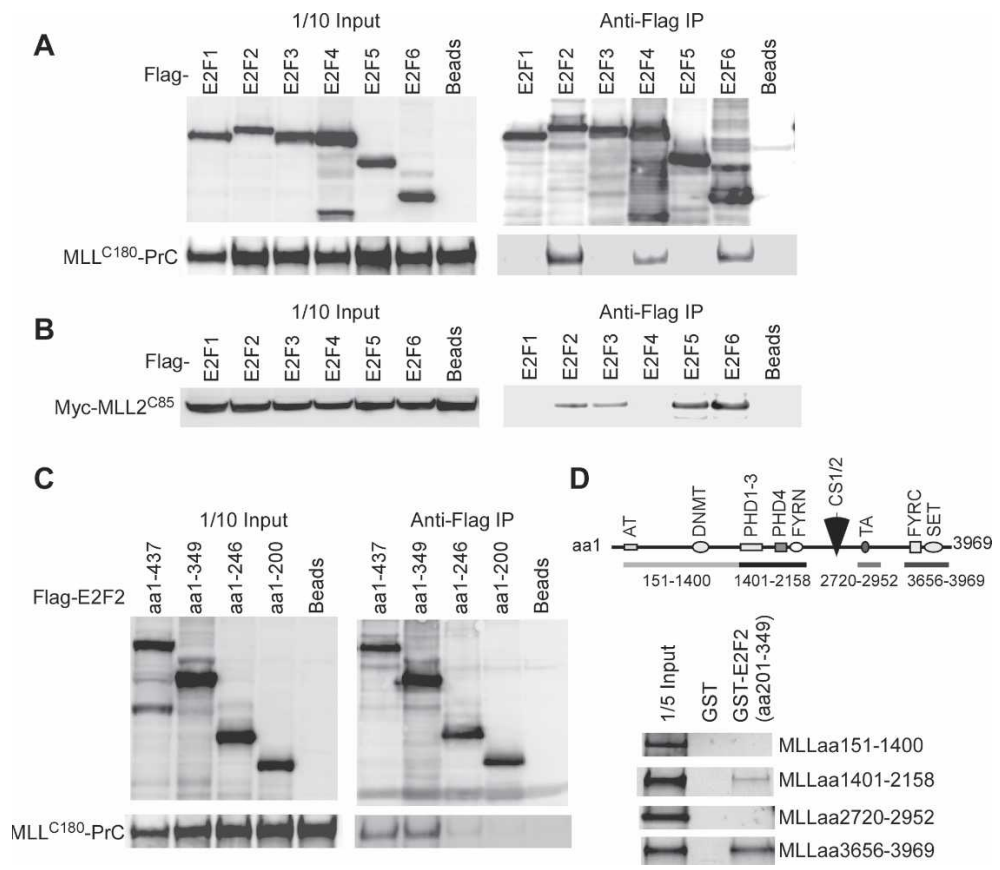

Figure 7. MLL target through E2Fs for cell cycle gene regulation. $(A, B)$ Various Flag-tagged E2Fs were coexpressed with C-terminal Protein C (PrC)-tagged full-length MLL (MLL $\left.{ }^{\mathrm{FL}}-\mathrm{PrC}\right)(A)$ or Myc-tagged MLL2 C terminus (amino acids 2061-2715) (B) in 293 T cells. Cellular extracts were subjected to antiFlag immunoprecipitation assays. Immunoprecipitates were analyzed by anti-Flag and anti-PrC $(A)$ or anti-Myc Western blots $(B) .(C)$ Flag-tagged deletion mutants of E2F2 were coexpressed with $\mathrm{MLL}^{\mathrm{FL}}-\mathrm{PrC}$ in $293 \mathrm{~T}$ cells before being subjected to anti-Flag immunoprecipitation assays. Coprecipitated processed MLL ${ }^{\mathrm{C} 180}$-PrC was detected by anti-PrC antibody. $(D)$ ${ }^{35} \mathrm{~S}$-methionine-labeled in vitro transcribed/translated MLL fragments incubated with either GST or GST-E2F2 (amino acids 201-349) were subjected to GST pull-down assays. Interactions were detected by autoradiography.
Cyclin genes through interactions with E2Fs, resulting in methylation of histone $\mathrm{H} 3$ at $\mathrm{K} 4$ and activation of these cell cycle progression genes. The up-regulation of p16 $6^{\text {Ink } 4 a}$ in Taspase1-null cells could be related to noncleavage of MLLs, but apparently involves a different mechanism.

Taspase $1^{-/-}$cells are resistant to oncogenic transformations and Taspase1 is overexpressed in many cancer cell lines

After establishing the importance of Taspase1 in cell proliferation, one critical question is whether Taspase 1 plays a role in oncogenesis. To examine this possibility, we tested whether deficiency of Taspase 1 confers resistance to oncogenic transformation. Taspase $1^{-/-}$cells are significantly more resistant to E1a/Ras-, Myc/Ras-, and DNp53/Ras-induced transformation, determined by the colony formation on soft agar (Fig. 8C). Of note, Cyclin $E 1^{-/} ; 2^{-/-}$MEFs also showed resistance to oncogenic transformation (Geng et al. 2003) and mice with increased gene dosage of $p 16^{\operatorname{Ink} 4 a} /$ Arf locus also showed resistance to cancer development (Matheu et al. 2004). Furthermore, Western blot analyses of the NCI-60 panel of cells demonstrated that Taspase 1 is commonly overexpressed in cancer cell lines (Fig. 8D).

\section{Discussion}

Site-specific proteolysis is involved in multiple biological processes. The identification of the evolutionarily conserved Taspase 1 in processing MLL suggests a critical regulation implemented by Taspase1 in the proper execution of affected signaling pathways. Here we report the first loss-of-function genetic analysis of Taspase 1 in mice. Taspase1-deficient newborns exhibit classic homeotic transformations, confirming the role of Taspase 1 in regulating body patterning. Importantly, our analyses of Taspase $1^{-/-}$mice uncover a surprising connection between Taspase 1 and cell proliferation. There are several lines of phenotypic evidence indicating an intrinsic role of Taspase 1 in cell cycle control. First, in a whole organism setting, Taspase1-null mice are smaller than their wild-type littermates. Second, MEFs deficient for Taspase1 proliferate poorly. Third, acute deletion of Taspase1 in vivo results in impaired expansion of DP thymocytes, confirming that Taspase 1 functions in a cell autonomous fashion. Mechanistic studies revealed a deregulated expression of key cell cycle regulators, including Cyclins $E, A$, and $B$, and $p 16^{\operatorname{Ink} 4 a}$. We show a direct regulation of these genes by Taspase1 through MLL cleavage. The uncleaved full-length precursor MLL ${ }^{\mathrm{FL}}$ is inefficient in histone $\mathrm{H} 3$ methylation both in vivo and in vitro. MLL proteolysis by Taspase1 is required to generate a fully functional mature MLL ${ }^{\mathrm{N} 320 / \mathrm{C} 180}$ heterodimer. Although the precise mechanism whereby Taspase1 activates MLL proteins remains unclear, cleavage-induced conformational changes likely render proper folding of MLLs to enhance their enzymatic activity and/or facilitate the assembly of functional MLL complexes. Furthermore, we showed that MLLs interact with E2Fs, core transcription factors of the cell cycle, to modulate the expression of Cyclins. Finally, the proliferation defects in MEFs bearing homozygous noncleavable MLL and MLL2 further demonstrate that MLLs are critical Taspase1 substrates in Taspase1-mediated cell cycle control. Taken together, our data are consistent with a model in which full-length precursor MLLs, following cleavage by Taspase1, target to Cyclins through their interactions with E2Fs to methylate histone $\mathrm{H} 3$ at K4, thus activating cell cycle regulatory genes. 

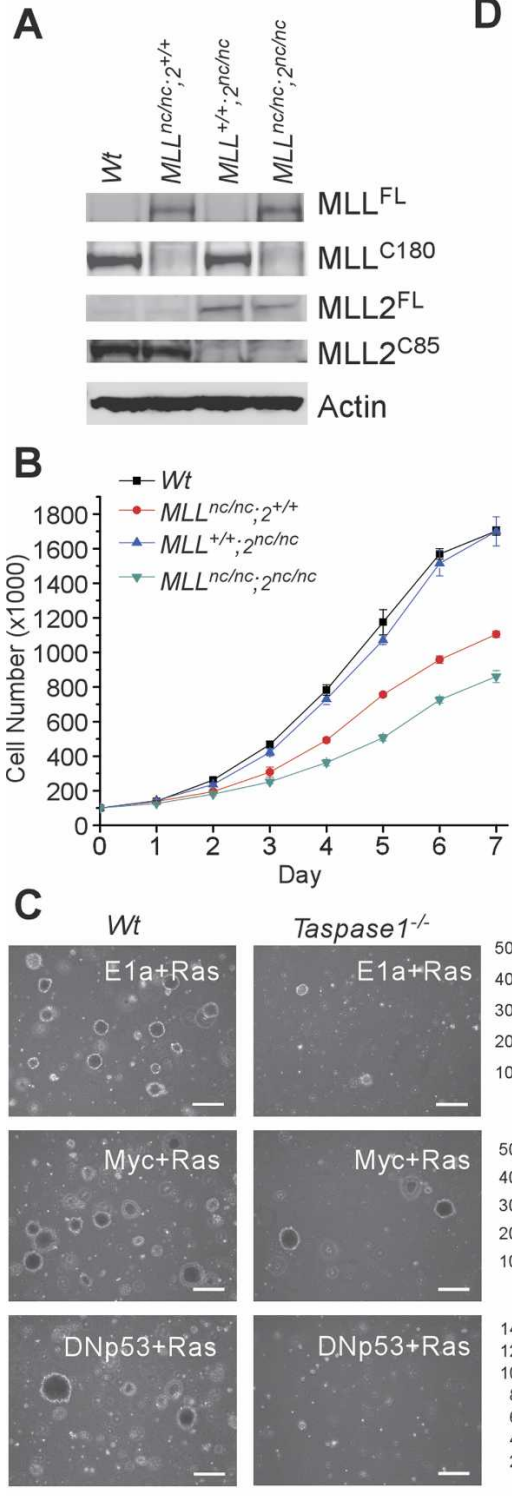

D
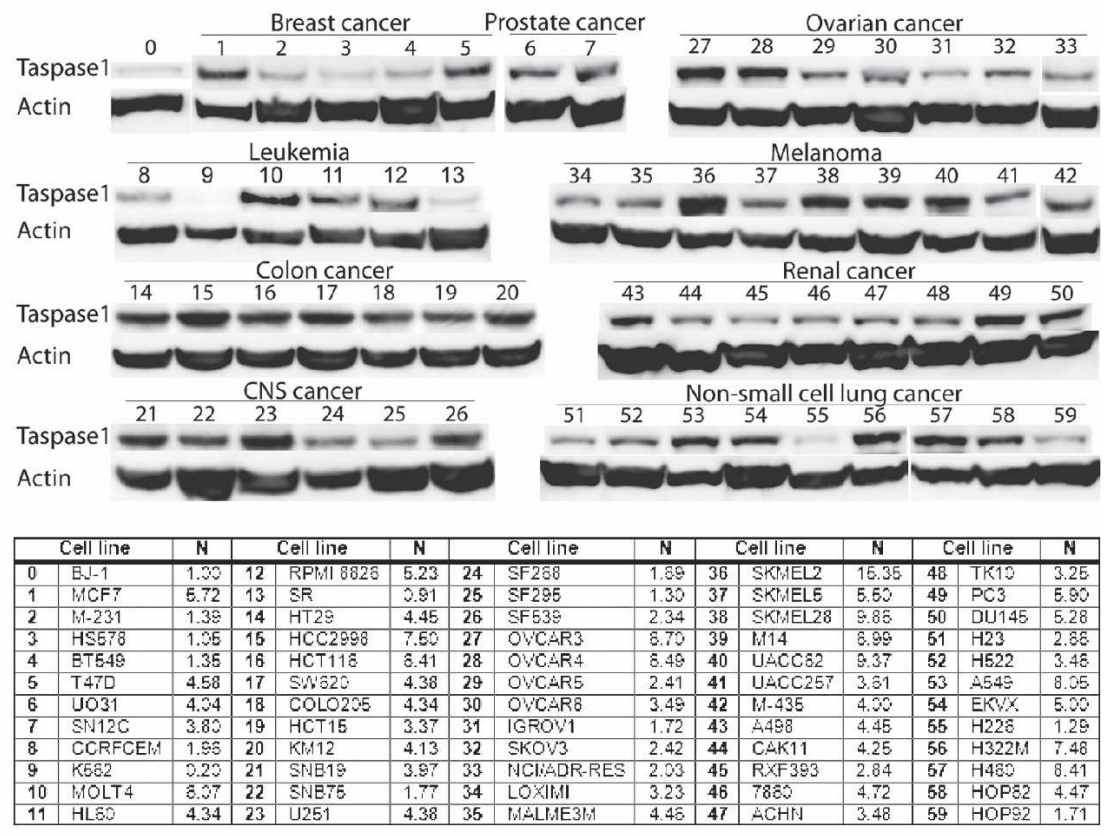
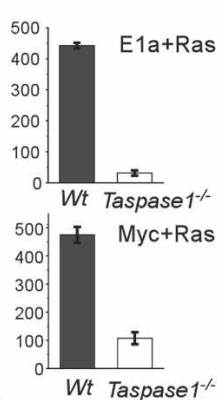

140.

\section{$\mathrm{E}$}

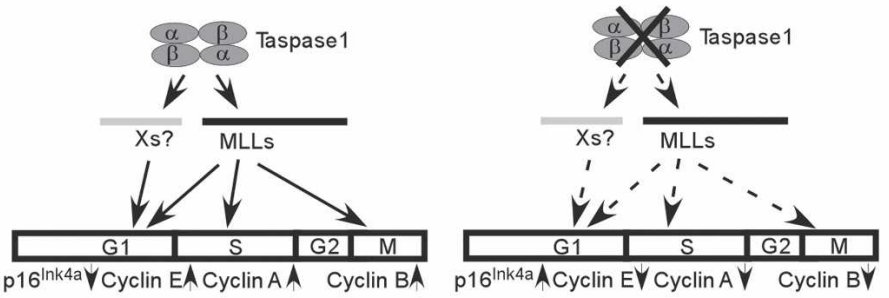

Figure 8. MLLs are crucial substrates for Taspase1-coordinated cell proliferation, and Taspase $1^{-/-}$cells exhibit increased resistance to oncogenic transformation. (A) Western blot analyses confirm the loss of indicated proteolysis of MLL and/or MLL2 in primary MEFs bearing different noncleavable MLL and MLL2 knock-in alleles. $(B)$ Cell proliferation curves of MEFs bearing $M L L^{n c / n c}$ and/or $M L L 2^{n c / n c}$ alleles are presented. Replicate cultures of $1 \times 10^{5}$ cells per 6-cm dish were plated on day 0, and cells were counted each day for seven consecutive days. Experiments were performed using passage 2 primary MEFs. Data shown as mean \pm SD were obtained from three independent lines of MEFs with the indicated genotype. (C) Primary MEFs transduced with the indicated oncogenes were plated on soft agar. Positive colonies (diameter $>0.2 \mathrm{~mm}$ ) were scored $2-3 \mathrm{wk}$ after initial plating. Bar, $0.4 \mathrm{~mm}$. Experiments were performed using passage 2 primary MEFs. Data shown as mean \pm SD were obtained from three independent experiments. $(D)$ Taspase 1 is overexpressed in many human cancer cell lines. (Upper panel) Western blot analyses of the expression of Taspase1 of NCI-60 cell lines. The expression of Taspase1 in human BJ-1 cells was set at 1 (Lower table). N denotes fold expression of Taspase1 in cancer cell lines over BJ-1, which was normalized with actin. $(E)$ Schematic models depict Taspasel orchestrating cell cycle progression through cleavage of nuclear factors, including MLLs to regulate transcription of $p 16^{\text {Ink4a }}$ and Cyclins. X denotes yet identified Taspase1 substrate(s) involved in cell cycle regulation.

Interestingly, recent genetic studies in Drosophila also implicate a positive role played by trithorax, the invertebrate counterpart of vertebrate MLL, in facilitating cell proliferation. Drosophila embryos carrying a null (trx ${ }^{B 11}$ ) and a hypomorphic allele $\left(\operatorname{trx}^{E 3}\right.$ or trx $\left.{ }^{\text {YY16}}\right)$ of trithorax displayed impaired BrdU incorporation in larval brains
(Muyrers-Chen et al. 2004). These hypomorphic alleles encode a noncleavable $\left(\operatorname{trx}^{E 3}\right)$ and a SET domain deleted trithorax $\left(\right.$ trX $\left.^{T Y 16}\right)$ (Breen 1999), indicating the requirement of Taspase1-mediated proteolytic activation and HMT activity for a full trx function. Although MLL has been shown to activate $\mathrm{p} 27^{\mathrm{Kip} 1}$ expression in SV40 trans- 
formed MEFs, whether this reflects the physiological function of MLL remains to be determined (Milne et al. 2005; Xia et al. 2005). The early embryonic lethality associated with MLL homozygous disruption precludes detailed studies of its function in the cell cycle (Yu et al. 1995). Our studies on Taspase $1^{-/-}$and $M L L^{n c / n c} ; 2^{n c / n c}$ cells provide clear genetic and biochemical evidence that mammalian MLLs regulate cell cycle progression, which is further modulated by Tasapse1.

Layers of modulation between cell proliferation sensors (e.g., receptor tyrosine kinases) and executors (e.g., E2Fs) help integrate signals to organize temporally controlled reciprocal expression of activators (e.g., Cyclins) and inhibitors (e.g., CdkIs), ensuring an accurate cell cycle decision. Taspase1-mediated cell cycle regulation provides a novel paradigm in which a site-specific protease participates in orchestrating these events through cleavage of nuclear factors for gene regulation (Fig. 8E). In the absence of Taspase1, cell cycle progression is deregulated, with decreased Cyclins and increased $p 16^{\operatorname{Ink} 4 a}$. Although Taspase1 deficiency does not affect Cyclin $D$ expression, up-regulated $p 16^{\text {Ink } 4 a}$ inhibits D type Cdk complexes. Furthermore, reduced expression of Cyclin E, A, and B affects the activity of respective Cyclin/Cdk complexes. Through panoramic inactivation of different classes of Cyclin/Cdk complexes, Taspase1 inhibition apparently provides a more efficient targeting strategy than those antagonizing individual Cdks. Importantly, acute deletion of Taspasel did not lead to lethality in mice, which further validate its potential use as a drug target. Analysis of the requirement for Taspase1 in tumor initiation and/or maintenance using a murine tumor model will further address the feasibility of targeting Taspase1 as anticancer therapeutics.

Taspase1, a member of the Asparaginase_2 family, apparently evolves from enzymes metabolizing asparagine or N-linked glycoproteins to cleave nuclear factors after an aspartate to activate their full transcriptional regulatory activity in multiple biological processes. The current study highlights the importance of Taspase 1 in two important biological processes: segmental identity and cell proliferation. We show that it participates in the expression of Hox genes for body segmentation, and $C y$ clin/CdkI genes for cell proliferation. With the expanding repertoire of Taspasel substrates and the lack of complete understanding of $p 16^{\text {Ink } 4 a}$ activation in the absence of Taspase1, it is tempting to suggest the existence of additional unidentified Taspase1 substrates whose functions are modulated by proteolysis. Systematic identification of such substrates is critical for a full appreciation of the extent of biological processes regulated by Taspase1. Proteases execute their functions through irreversible protein modifications. Thus, their activity tends to be tightly regulated. Although Taspase1 seems to exert its function constitutively, it is foreseeable that such an activity may be regulated under specific circumstances. Future studies on identifying novel Taspase1 substrates, characterizing the biology of proteolysis of each substrate, and investigating the regulation of each proteolytic event will shed light on how Taspase1, an evolutionarily conserved protease, integrates multiple signaling pathways through site-specific proteolysis.

\section{Materials and methods}

\section{Targeting the Taspase1 genomic locus}

The murine Taspase 1 genomic locus sequences were obtained from the Ensembl database (http://www.ensembl.org). The targeting construct has a $\operatorname{lox} P$ site upstream of exon 9 . A $\operatorname{lox} P$ flanked $p P G K n e o$ cassette was inserted into the intron between exons 9 and 10. Successfully targeted RW4 embryonic stem (ES) cells (129SvJ) were determined by Southern blot analyses, followed by a transient transfection with CMV-Cre to generate Taspase $1^{+/-}$ES clones with a deletion of exon 9 and pPGKneo. ES cells with a heterozygous deletion of Taspase1 were injected into $\mathrm{C} 57 \mathrm{Bl} / 6$ blastocysts.

In vitro cleavage assays and quantitative RT-PCR analyses

In vitro cleavage assays and quantitative RT-PCR analysis were performed as described with minor modifications (Hsieh et al. 2003a). Fifty micrograms of whole-cell extracts were incubated with $1 \mu \mathrm{g}$ of purified rTaspase1 before being subjected to Western blot analyses. Oligo sequences are included in the Supplemental Material.

\section{Skeletal studies}

P1 newborns were sacrificed and stained as described using Alazarin red and Alcian blue for bone and cartilage, respectively (Yu et al. 1995).

\section{Cell cycle analyses}

Primary MEFs were pulsed with BrdU for $1 \mathrm{~h}$ and analyzed by FACSCalibur according to the manufacturer's manual (BD Pharmingen, FITC BrdU Flow Kit). To assess the quiescent population, asynchronized cells were cultured with BrdU for 24 $\mathrm{h}$ before analysis.

\section{Acute deletion of Taspase 1 in vivo}

Mice at $6 \mathrm{wk}$ of age with indicated genotypes were administered with three 400- $\mu$ intraperitoneal injections of pI-pC at days 1 , 3 , and 5. Treated mice were sacrificed and analyzed $7 \mathrm{~d}$ after final injection. The acute deletion of Taspase1 in thymus was assessed by PCR analyses.

\section{Cell cycle re-entry experiments}

Primary MEFs were serum deprived for $72 \mathrm{~h}$ in DMEM supplemented with $0.1 \%$ fetal bovine serum (FBS) before being refed with full medium supplemented with $10 \%$ serum for indicated periods of time and labeled with Tritium thymidine $1 \mathrm{~h}$ before harvest. Experiments were performed as described (Kozar et al. 2004). To determine the percentage of cells that actually reenter cell cycle, serum-deprived cells were stimulated with full medium supplemented with $10 \%$ serum in the presence of BrdU for $28 \mathrm{~h}$.

RNAi-mediated knockdown of p16 in MEFs

ShRNA specifically against mouse p16 (TRCN77816) was purchased from Mission shRNA clones (Sigma) and shRNA against firefly luciferase was used as a control. Wild-type and Tas- 
pase $^{-/-}$P1 MEFs were infected with letivirus expressing the indicated shRNA for $2 \mathrm{~d}$ before being subjected to an antibiotics selection with puromycin at $1 \mu \mathrm{g} / \mathrm{mL}$.

\section{ChIP assays}

ChIP assays were performed using the ChIP assay kit (Upstate Biotechnology). Antibodies utilized include anti-CT MLL, antihistone H3 (trimethyl K4, abcam 8580), and antihistone H3 (acetyl K9/K14, Upstate Biotechnology 06-599). Analyses were performed on ABI 7200 using gene-specific TaqMan probes. A GAPDH probe used as a negative control was previously described (Milne et al. 2005). Probe sequences are included in the Supplemental Material.

\section{HMT assays and on-bead in vitro proteolysis of $M L L^{F L}$}

The on-bead HMT assay has been described with minor modifications (Hughes et al. 2004). Three milligrams of cellular extracts from passage 3 asynchronized primary MEFs were incubated with or without $10 \mu \mathrm{g}$ of anti-CT MLL antibody overnight at $4^{\circ} \mathrm{C}$ with gentle rocking. Formed immune complexes were precipitated with $60 \mu \mathrm{L}$ of protein A beads (Amersham Biosciences) for $3 \mathrm{~h}$ at $4^{\circ} \mathrm{C}$. Bead-bound MLL complexes were split to two tubes: one for HMT assay, and one for on-bead cleavage assay. In brief, HMT assays include bead-bound MLL complexes, $2 \mu \mathrm{g}$ of histone $\mathrm{H} 3$ (Roche), and $2 \mu \mathrm{L}$ of SAM (Amersham Biosciences). Bead-bound MLL proteins were washed with cleavage buffer, incubated with $2 \mu \mathrm{g}$ of rTaspase 1 for $6 \mathrm{~h}$ to ensure a complete in vitro proteolysis of $\mathrm{MLL}^{\mathrm{FL}}$, resolved on SDS-PAGE, and detected by anti-CT MLL antibody.

\section{Coimmunoprecipitation and GST pull-down assays}

Coimmunoprecipitation assays were performed as described (Hsieh et al. 2003a). For GST pull-down assays, $5 \mu \mathrm{g}$ of purified GST or GST-E2F2 (amino acids 201-349) were bound to $30 \mu \mathrm{L}$ of Glutathione beads (Amersham Biosciences) before incubating with ${ }^{35}$ S-methionine-labeled MLL fragments (Promega TNT T7 Quick-Coupled Transcription/Translation Kit). Coprecipitated MLL fragments were subjected to SDS-PAGE and visualized by autoradiography. Pull-down assays were performed in the presence of $0.2 \% \mathrm{NP} 40,140 \mathrm{mM} \mathrm{NaCl}, 50 \mathrm{mM}$ Tris- $\mathrm{HCl}(\mathrm{pH} 8.0)$, $100 \mathrm{mM} \mathrm{NaF}$, and $200 \mu \mathrm{M}$ Sodium Orthovanadate.

\section{NCI-60 cancer cell lines}

Cell pellets from the NCI human tumor cell line panel were provided by the Developmental Therapeutics Program of the NCI. The Taspasel expression level was analyzed by ImageGauge (FujiFilm).

\section{Acknowledgments}

We thank S. Diane Hayward and Lee Ratner for critical comments on this manuscript. We thank Pat Nakatani, Kei-ichiro Ishiguro, Piotr Sicinski, Katarzyna Kozar, Qunyan Yu, and Yang Geng for providing reagents and technical advice. We thank Sheila Stewart for providing the control shRNA plasmid and Susan Holbeck for providing NCI-60 cell pellets. E.H.C. is supported by Searle Scholars Program, Mallinckrodt Jr. Foundation, and NCI Howard Temin Award. This work is supported by Mallinckrodt Jr. Foundation, NCI Howard Temin Award, and CA R01-119008 to J.J.H.

\section{References}

Ayton, P.M. and Cleary, M.L. 2001. Molecular mechanisms of leukemogenesis mediated by MLL fusion proteins. Oncogene 20: 5695-5707.

Blais, A. and Dynlacht, B.D. 2004. Hitting their targets: An emerging picture of E2F and cell cycle control. Curr. Opin. Genet. Dev. 14: 527-532.

Bracken, A.P., Ciro, M., Cocito, A., and Helin, K. 2004. E2F target genes: Unraveling the biology. Trends Biochem. Sci. 29: 409-417.

Breen, T.R. 1999. Mutant alleles of the Drosophila trithorax gene produce common and unusual homeotic and other developmental phenotypes. Genetics 152: 319-344.

Brown, M.S., Ye, J., Rawson, R.B., and Goldstein, J.L. 2000. Regulated intramembrane proteolysis: A control mechanism conserved from bacteria to humans. Cell 100: 391-398.

Canaani, E., Nakamura, T., Rozovskaia, T., Smith, S.T., Mori, T., Croce, C.M., and Mazo, A. 2004. ALL-1/MLL1, a homologue of Drosophila TRITHORAX, modifies chromatin and is directly involved in infant acute leukaemia. Br. J. Cancer 90: 756-760.

Capecchi, M.R. 1997. Hox genes and mammalian development. Cold Spring Harb. Symp. Quant. Biol. 62: 273-281.

Daser, A. and Rabbitts, T.H. 2004. Extending the repertoire of the mixed-lineage leukemia gene MLL in leukemogenesis. Genes \& Dev. 18: 965-974.

DeJong, J. and Roeder, R.G. 1993. A single cDNA, hTFIIA/ $\alpha$, encodes both the p35 and p19 subunits of human TFIIA. Genes \& Dev. 7: 2220-2234.

Dou, Y., Milne, T.A., Tackett, A.J., Smith, E.R., Fukuda, A., Wysocka, J., Allis, C.D., Chait, B.T., Hess, J.L., and Roeder, R.G. 2005. Physical association and coordinate function of the H3 K4 methyltransferase MLL1 and the H4 K16 acetyltransferase MOF. Cell 121: 873-885.

Dyson, N. 1998. The regulation of E2F by pRB-family proteins. Genes \& Dev. 12: 2245-2262.

Geng, Y., Yu, Q., Sicinska, E., Das, M., Schneider, J.E., Bhattacharya, S., Rideout, W.M., Bronson, R.T., Gardner, H., and Sicinski, P. 2003. Cyclin E ablation in the mouse. Cell 114: 431-443.

Gilliland, D.G., Jordan, C.T., and Felix, C.A. 2004. The molecular basis of leukemia. Hematology Am Soc Hematol Educ Program 2004: 80-97.

Hanson, R.D., Hess, J.L., Yu, B.D., Ernst, P., van Lohuizen, M., Berns, A., van der Lugt, N.M., Shashikant, C.S., Ruddle, F.H., Seto, M., et al. 1999. Mammalian Trithorax and polycomb-group homologues are antagonistic regulators of homeotic development. Proc. Natl. Acad. Sci. 96: 1437214377.

Hoiby, T., Mitsiou, D.J., Zhou, H., Erdjument-Bromage, H., Tempst, P., and Stunnenberg, H.G. 2004. Cleavage and proteasome-mediated degradation of the basal transcription factor TFIIA. EMBO J. 23: 3083-3091.

Hsieh, J.J., Cheng, E.H., and Korsmeyer, S.J. 2003a. Taspase1: A threonine aspartase required for cleavage of MLL and proper HOX gene expression. Cell 115: 293-303.

Hsieh, J.J., Ernst, P., Erdjument-Bromage, H., Tempst, P., and Korsmeyer, S.J. 2003b. Proteolytic cleavage of MLL generates a complex of $\mathrm{N}$ - and $\mathrm{C}$-terminal fragments that confers protein stability and subnuclear localization. Mol. Cell. Biol. 23: 186-194.

Hughes, C.M., Rozenblatt-Rosen, O., Milne, T.A., Copeland, T.D., Levine, S.S., Lee, J.C., Hayes, D.N., Shanmugam, K.S., Bhattacharjee, A., Biondi, C.A., et al. 2004. Menin associates with a trithorax family histone methyltransferase complex 
and with the hoxc8 locus. Mol. Cell 13: 587-597.

Huntsman, D.G., Chin, S.F., Muleris, M., Batley, S.J., Collins, V.P., Wiedemann, L.M., Aparicio, S., and Caldas, C. 1999. MLL2, the second human homolog of the Drosophila trithorax gene, maps to $19 \mathrm{q} 13.1$ and is amplified in solid tumor cell lines. Oncogene 18: 7975-7984.

Itahana, K., Dimri, G., and Campisi, J. 2001. Regulation of cellular senescence by p53. Eur. J. Biochem. 268: 2784-2791.

Jacobs, J.J., Kieboom, K., Marino, S., DePinho, R.A., and van Lohuizen, M. 1999. The oncogene and Polycomb-group gene bmi-1 regulates cell proliferation and senescence through the ink4a locus. Nature 397: 164-168.

Julien, E. and Herr, W. 2003. Proteolytic processing is necessary to separate and ensure proper cell growth and cytokinesis functions of HCF-1. EMBO J. 22: 2360-2369.

Khan, J.A., Dunn, B.M., and Tong, L. 2005. Crystal structure of human Taspase1, a crucial protease regulating the function of MLL. Structure 13: 1443-1452.

Kmita, M. and Duboule, D. 2003. Organizing axes in time and space: 25 years of colinear tinkering. Science 301: 331-333.

Kozar, K., Ciemerych, M.A., Rebel, V.I., Shigematsu, H., Zagozdzon, A., Sicinska, E., Geng, Y., Yu, Q., Bhattacharya, S., Bronson, R.T., et al. 2004. Mouse development and cell proliferation in the absence of D-cyclins. Cell 118: 477-491.

Kuhn, R., Schwenk, F., Aguet, M., and Rajewsky, K. 1995. Inducible gene targeting in mice. Science 269: 1427-1429.

Ma, D., Watanabe, H., Mermelstein, F., Admon, A., Oguri, K., Sun, X., Wada, T., Imai, T., Shiroya, T., Reinberg, D., et al. 1993. Isolation of a cDNA encoding the largest subunit of TFIIA reveals functions important for activated transcription. Genes \& Dev. 7: 2246-2257.

Matheu, A., Pantoja, C., Efeyan, A., Criado, L.M., Martin-Caballero, J., Flores, J.M., Klatt, P., and Serrano, M. 2004. Increased gene dosage of Ink4a/Arf results in cancer resistance and normal aging. Genes \& Dev. 18: 2736-2746.

Mazo, A.M., Huang, D.H., Mozer, B.A., and Dawid, I.B. 1990. The trithorax gene, a trans-acting regulator of the bithorax complex in Drosophila, encodes a protein with zinc-binding domains. Proc. Natl. Acad. Sci. 87: 2112-2116.

McGinnis, W. and Krumlauf, R. 1992. Homeobox genes and axial patterning. Cell 68: 283-302.

Milne, T.A., Briggs, S.D., Brock, H.W., Martin, M.E., Gibbs, D., Allis, C.D., and Hess, J.L. 2002. MLL targets SET domain methyltransferase activity to Hox gene promoters. Mol. Cell 10: $1107-1117$.

Milne, T.A., Hughes, C.M., Lloyd, R., Yang, Z., RozenblattRosen, O., Dou, Y., Schnepp, R.W., Krankel, C., Livolsi, V.A., Gibbs, D., et al. 2005. Menin and MLL cooperatively regulate expression of cyclin-dependent kinase inhibitors. Proc. Natl. Acad. Sci. 102: 749-754.

Muyrers-Chen, I., Rozovskaia, T., Lee, N., Kersey, J.H., Nakamura, T., Canaani, E., and Paro, R. 2004. Expression of leukemic MLL fusion proteins in Drosophila affects cell cycle control and chromosome morphology. Oncogene 23: 86398648.

Nakamura, T., Mori, T., Tada, S., Krajewski, W., Rozovskaia, T., Wassell, R., Dubois, G., Mazo, A., Croce, C.M., and Canaani, E. 2002. ALL-1 is a histone methyltransferase that assembles a supercomplex of proteins involved in transcriptional regulation. Mol. Cell 10: 1119-1128.

Nevins, J.R. 2001. The Rb/E2F pathway and cancer. Hum. Mol. Genet. 10: 699-703.

Paul, W.E. 2003. Fudamental immunology. Lippincott Williams \& Wilkins, Philadelphia, PA.

Petruk, S., Sedkov, Y., Smith, S., Tillib, S., Kraevski, V., Nakamura, T., Canaani, E., Croce, C.M., and Mazo, A. 2001. Tri- thorax and dCBP acting in a complex to maintain expression of a homeotic gene. Science 294: 1331-1334.

Popovic, R. and Zeleznik-Le, N.J. 2005. MLL: How complex does it get? J. Cell. Biochem. 95: 234-242.

Ringrose, L. and Paro, R. 2004. Epigenetic regulation of cellular memory by the Polycomb and Trithorax group proteins. Annu. Rev. Genet. 38: 413-443.

Rowley, J.D. 1998. The critical role of chromosome translocations in human leukemias. Annu. Rev. Genet. 32: 495-519.

Saklatvala, J., Nagase, H., and Salvesen, G., eds. 2002. Biochemical Society Symposia vol. 70: Proteases and the regulation of biological processes. Portland Press, London.

Santos-Rosa, H., Schneider, R., Bannister, A.J., Sherriff, J., Bernstein, B.E., Emre, N.C., Schreiber, S.L., Mellor, J., and Kouzarides, T. 2002. Active genes are tri-methylated at K4 of histone H3. Nature 419: 407-411.

Sherr, C.J. and Roberts, J.M. 1999. CDK inhibitors: Positive and negative regulators of G1-phase progression. Genes \& Dev. 13: $1501-1512$.

Storre, J., Elsasser, H.P., Fuchs, M., Ullmann, D., Livingston, D.M., and Gaubatz, S. 2002. Homeotic transformations of the axial skeleton that accompany a targeted deletion of E2f6. EMBO Rep. 3: 695-700.

Thornberry, N.A. and Lazebnik, Y. 1998. Caspases: Enemies within. Science 281: 1312-1316.

Trimarchi, J.M. and Lees, J.A. 2002. Sibling rivalry in the E2F family. Nat. Rev. Mol. Cell Biol. 3: 11-20.

Wysocka, J., Swigut, T., Milne, T.A., Dou, Y., Zhang, X., Burlingame, A.L., Roeder, R.G., Brivanlou, A.H., and Allis, C.D. 2005. WDR5 associates with histone H3 methylated at K4 and is essential for H3 K4 methylation and vertebrate development. Cell 121: 859-872.

Xia, Z.B., Popovic, R., Chen, J., Theisler, C., Stuart, T., Santillan, D.A., Erfurth, F., Diaz, M.O., and Zeleznik-Le, N.J. 2005. The MLL fusion gene, MLL-AF4, regulates cyclin-dependent kinase inhibitor CDKN1B (p27kip1) expression. Proc. Natl. Acad. Sci. 102: 14028-14033.

Ye, Y. and Fortini, M.E. 2000. Proteolysis and developmental signal transduction. Semin. Cell Dev. Biol. 11: 211-221.

Yokomori, K., Admon, A., Goodrich, J.A., Chen, J.L., and Tjian, R. 1993. Drosophila TFIIA-L is processed into two subunits that are associated with the TBP/TAF complex. Genes \& Dev. 7: 2235-2245.

Yokoyama, A., Kitabayashi, I., Ayton, P.M., Cleary, M.L., and Ohki, M. 2002. Leukemia proto-oncoprotein MLL is proteolytically processed into 2 fragments with opposite transcriptional properties. Blood 100: 3710-3718.

Yokoyama, A., Wang, Z., Wysocka, J., Sanyal, M., Aufiero, D.J., Kitabayashi, I., Herr, W., and Cleary, M.L. 2004. Leukemia proto-oncoprotein MLL forms a SET1-like histone methyltransferase complex with menin to regulate Hox gene expression. Mol. Cell. Biol. 24: 5639-5649.

Yu, B.D., Hess, J.L., Horning, S.E., Brown, G.A., and Korsmeyer, S.J. 1995. Altered Hox expression and segmental identity in MLL-mutant mice. Nature 378: 505-508.

Yu, B.D., Hanson, R.D., Hess, J.L., Horning, S.E., and Korsmeyer, S.J. 1998. MLL, a mammalian trithorax-group gene, functions as a transcriptional maintenance factor in morphogenesis. Proc. Natl. Acad. Sci. 95: 10632-10636.

Zhou, H., Spicuglia, S., Hsieh, J.J., Mitsiou, D.J., Hoiby, T., Veenstra, G.J., Korsmeyer, S.J., and Stunnenberg, H.G. 2006. Uncleaved TFIIA is a substrate for taspase 1 and active in transcription. Mol. Cell. Biol. 26: 2728-2735. 


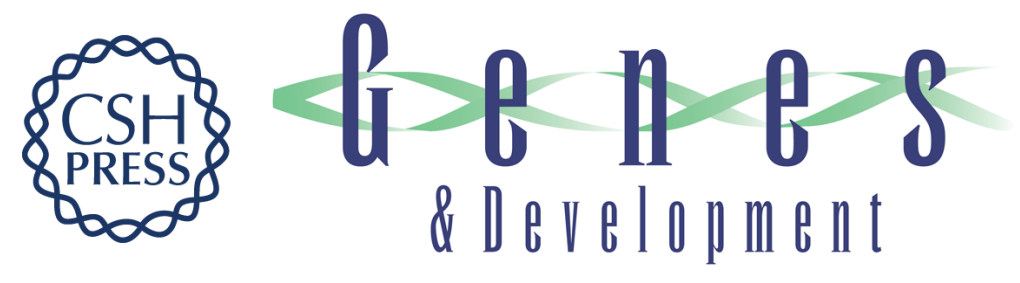

\section{Proteolysis of MLL family proteins is essential for Taspase1-orchestrated cell cycle progression}

Shugaku Takeda, David Y. Chen, Todd D. Westergard, et al.

Genes Dev. 2006, 20:

Access the most recent version at doi:10.1101/gad.1449406

Supplemental http://genesdev.cshlp.org/content/suppl/2006/09/05/20.17.2397.DC1
Material

References This article cites 53 articles, 24 of which can be accessed free at:

http://genesdev.cshlp.org/content/20/17/2397.full.html\#ref-list-1

License

Email Alerting Receive free email alerts when new articles cite this article - sign up in the box at the top

Service right corner of the article or click here.

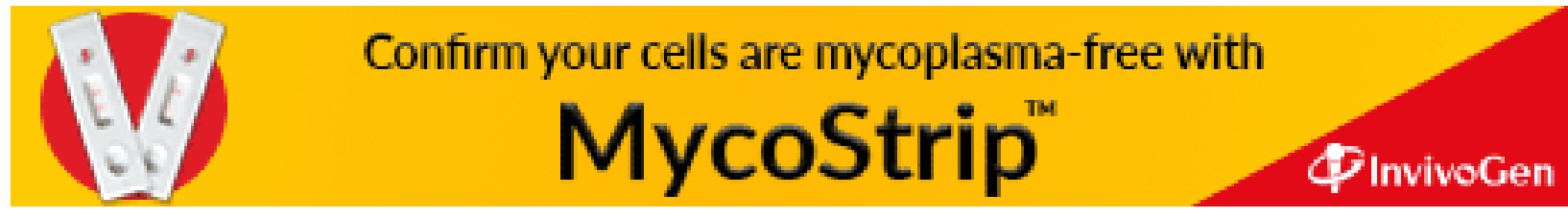

